\title{
Advanced Optical Sensing Reveals Diamond-Like Stress Concentration Patterns on the Surface of Human Cornea
}

Joseph Antony S*

School of Chemical and Process Engineering, UK

ISSN: 2576-8840

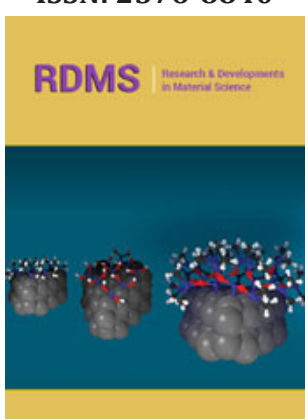

${ }^{* 1}$ Corresponding author: Joseph Antony S, School of Chemical and Process Engineering, University of Leeds, Leeds LS2 9JT, UK

Submission: 1-in⿴囗十 March 18, 2019

Published: 眥 March 25, 2019

Volume 10 - Issue 2

How to cite this article: Joseph A S. Advanced Optical Sensing Reveals Diamond-Like Stress Concentration Patterns on the Surface of Human Cornea. Res Dev Material Sci. 10(2). RDMS.000733.2019.

DOI: 10.31031/RDMS.2019.10.000733

Copyright@ Joseph Antony S, This article is distributed under the terms of the Creative Commons Attribution 4.0 International License, which permits unrestricted use and redistribution provided that the original author and source are credited.

\section{Opinion}

Cornea is the front window of eye, and assessing its health is important to detect any abnormalities and treating early. Until now, information on how human eye elements distribute shear stress remained scarce. In a research study conducted recently, diamondshaped stress concentration patterns on a healthy human cornea have been revealed (Figure 1). Unlike scanning the internal structures of the human body using X-ray, this new approach $[1,2]$ for measuring stress distribution on human cornea does not require the use of X-ray and is therefore friendlier to the biological elements of cornea. Furthermore, the stress measurements on cornea can be made in-vivo, by using a non-invasive method employing white light source.
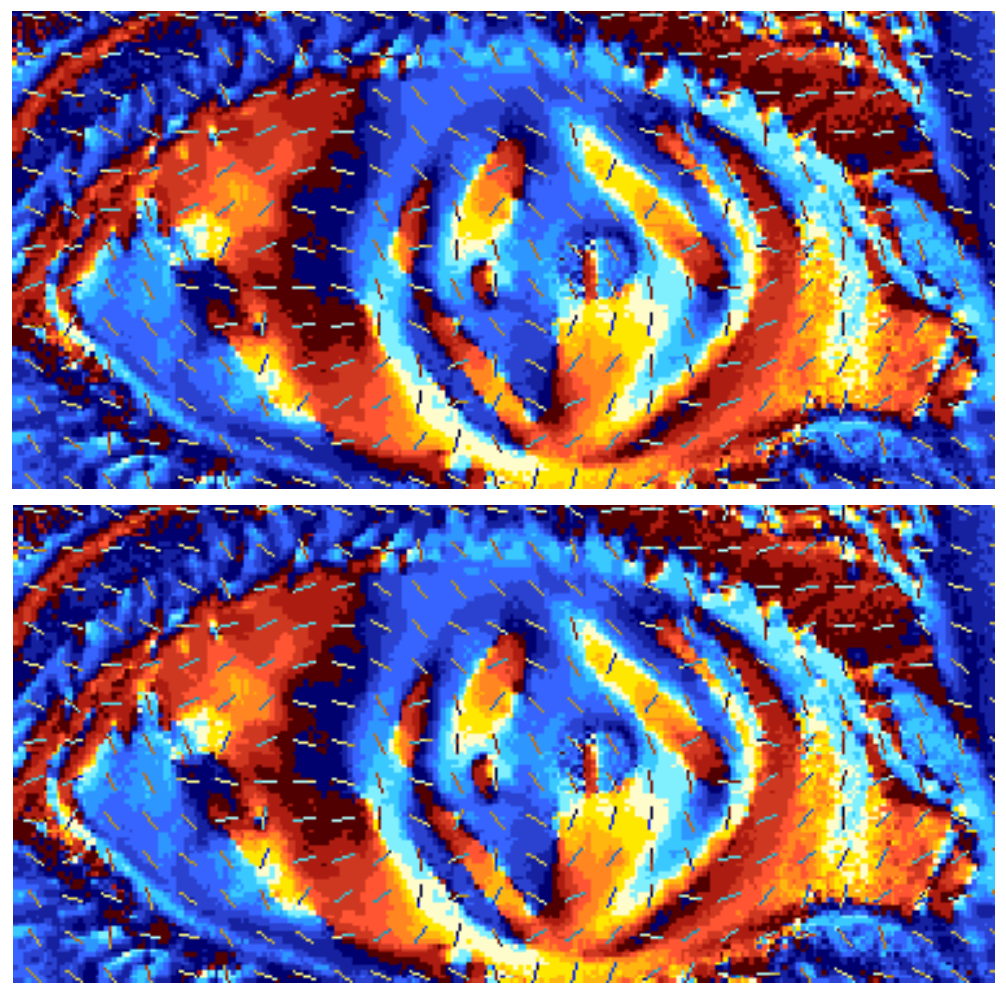

Figure 1: A typical diamond shape maximum shear stress concentration map of human cornea, sensed using birefringent polariscope. The dotted lines show the direction of major principal stress acting on the surface of the cornea $[1$.

It is like taking a picture of us using a camera with a white light source. The new application could open up better understanding of the variations of stress concentration profiles in the human eyes more easily, even at different times of the day and seasons in the future", says Dr Joseph Antony, Associate Professor in the University of Leeds in UK, who published this research. Fatigue failures usually originate at shear stress concentration points in materials. 
So, by visualising any abnormal distribution of shear stress in the eyes in the early stages of patients, this could help to assess the health of cornea and to suitably treat the abnormal population. Similar to thermometers being used for monitoring the general health in humans, simple methods such as this should help to quantify stresses concentrations in the eyes more easily in future.

The University of Leeds is ranked in the top 10 universities for research power in UK according to the Research Assessment
Exercise in 2014; top 10 universities in the UK in the Guardian University Guide 2019; and in the top 100 universities in the world (QS World University Rankings 2019).

\section{References}

1. Antony SJ (2015) Imaging shear stress distribution and evaluating the stress concentration factor of the human eye. Scientific Reports 5: 8899.

2. Antony SJ (2016) In vivo pattern recognition and digital image analysis of shear stress distribution in human eye. International Journal on Cybernetics \& Informatics 5(2): 1-8. 